\title{
A COPA DO MUNDO DE 1950 E SUA INSERÇÃO NA PRODUÇÃo DO ESPAÇO URBANO BRASILEIRO
}

\section{THE FOOTBALL WORLD CUP OF 1950 AND ITS INSERTION IN THE PRODUCTION OF BRAZILIAN URBAN SPACE}

\author{
Gilmar Mascarenhas \\ Doutor em Geografia Humana \\ UERJ \\ gmascarenhas@uerj.br
}

\begin{abstract}
Resumo:
A Copa do Mundo de 1950 apresenta uma espacialidade que reflete o estágio de evolução da rede urbana brasileira de então, com seus resquícios de concentração litorânea e evidente hegemonia das duas metrópoles nacionais, com destaque para o Rio de Janeiro. No tocante à escala intra-urbana, que mais interessa neste trabalho, este megaevento esportivo perfez um baixo impacto em nosso parque de estádios. Argumentamos que não apenas naquele contexto histórico a realização de uma copa do mundo agregava muito menor volume de investimento material, mas sobretudo que já estava em curso no futebol brasileiro um consistente processo de popularização que se refletia na constante ampliação dos estádios preexistentes e no crescente envolvimento do poder estatal na produção do espetáculo.
\end{abstract}

Palavras-chave: futebol - estádios -urbanização - Brasil - copa do mundo 1950

\begin{abstract}
:
The spatiality of the World Cup of 1950 reflects the stage of evolution of the Brazilian urban network back then, still showing coastal concentration and the hegemony of the two national metropolises, with emphasis in Rio de Janeiro. In regards of the intra-urban scale, which matters the most in this work, this sport mega-event produced a low impact in our stadiums. We can argue that not only in that historical context the realization of a World Cup could aggregate a much smaller volume of material investment, but above everything, that in the Brazilian soccer there already were in course a consistent process of popularization. This process was reflected in the constant amplification of already existing stadiums and in the growing involvement of state power in the production of the spectacle.
\end{abstract}

Key-words: football - stadia - urbanization - Brazil - 1950 World Cup 


\section{Introdução}

Os estudos acerca da relação entre megaeventos esportivos e cidades têm se pautado pela análise e dimensionamento do conjunto dos efeitos do evento sobre o espaço urbano (McKAY, M. \& PLUMB, 2005; PREUSS, 2004; OWEN, 2005; YOUNG \& TOMLINSON, 2006; STEINER, 1999; STAVRIDES, 2008; ANDRANOVICH, BURBANK e HEYNG, 2001; ANDRANOVICH, 2002; HAYNES, 2000). Tais efeitos são tomados como impactos ou como legado, variando o uso da terminologia conforme a perspectiva teórica do investigador ${ }^{\mathrm{i}}$. Nossas investidas neste campo, iniciadas em 2002, têm como foco o estudo dos impactos e das resistências locais, bem como da coalizão de interesses e agentes em torno da produção do megaevento esportivo ${ }^{\mathrm{ii}}$. Neste momento, propomos um encaminhamento alternativo: pensar o megaevento esportivo como constitutivo do processo de produção do espaço. Em outras palavras, não como elemento "exterior" que repentinamente invade e (des)organiza o território e o movimento habitual da cidade, mas enquanto um constructo que tem raízes locais, no próprio devir urbano.

Temos ciência de que esta perspectiva analítica alternativa convém mais plenamente aos megaeventos esportivos ocorridos no período anterior à "virada olímpica" (PRONI, 2008) e à radical transformação operada na economia do futebol,processos que se iniciam por volta de 1980 (PRONI, 2000; GIULIANOTI, 2002). Até então, as entidades globais (FIFA e COI) que controlam tais eventos eram bem menos exigentes no tocante aos investimentos necessários nas cidades-sede. Sobretudo, não havia ainda se construído plenamente a poderosa confluência de interesses entre tais eventos e as novas estratégias de gestão das cidades, no sentido da valorização e projeção competitiva de sua imagem global (o citymarketing), podendo incluir a "máquina urbana do crescimento" de que nos falam Logan e Molotch (1990). Neste sentido, os eventos eram bem mais discretos que os atuais, estes marcados pela monumentalidade, intervenções radicais no espaço urbano e orçamentos bilionários.Quando estudamos os Jogos Pan-americanos de 1963, na cidade de São Paulo (MASCARENHAS, 2011), nos deparamos exatamente com este contexto pregresso: o gigantismo das forças que governam e movimentam a produção do espaço 
urbano-metropolitano em relação às tímidas possibilidades de um evento esportivo, que então apenas se adaptou à cidade e à sua infraestrutura disponível.

Nesse momento, nosso foco está em 1950, quando o Brasil sediou a IV Copa do Mundo de Futebol masculino, acolhendo seleções de doze países em seis cidades-sede. Mesmo quando comparamos com outros megaeventos esportivos de seu tempo, realizados em outros países, pode-se admitir que muito pouco se estudou e se publicou sobre aquela copa. Em parte, podemos entender este relativo silencio pela dimensão trágica que representou a derrota inesperada da seleção brasileira, quando todas as comemorações já estavam preparadas (algumas já em plena execução), tamanha a confiança e certeza de todos na grande vitória nacional ${ }^{\mathrm{iii}}$.

Aos olhos do pesquisador, uma Copa do Mundo, como qualquer outro grande ritual coletivo, pode servir de porta de entrada para acessar aspectos fundamentais de uma sociedade em determinado momento histórico. Sendo um ritual esportivo, agrega toda uma dimensão de drama, de feitos heróicos e épicos. E nesse sentido, a Copa de 1950 foi uma das mais "dramáticas" da história, e por isso, ainda hoje, os registros que temos daquele certame se concentram na dramatização da derrota inesperada, não de uma seleção de jogadores de futebol, mas de toda uma "raça", de uma nação que queria apostar em seu futuro grandioso, seu "destino manifesto"; uma nação determinada a provar ao mundo a superação do atraso colonial e de suas desprezadas raízes "tupiniquins".

Do ponto de vista essencialmente geográfico, uma copa do mundo pode servir para ajudar a desvendar variados aspectos de uma determinada formação territorial e sua rede urbana, bem como a natureza (e conteúdos) da urbanização, além de propiciar a reflexão sobre os regionalismos, e tantos outros temas. O próprio universo das cidades escolhidas para sediar os jogos serve como "retrato" da hierarquia urbana em determinado contexto histórico; bem como pode nos falar do padrão de ocupação demográfica do território nacional, e assim revelar, em nosso caso, imensos "vazios" em 1950: todo o Centro-Oeste e Norte estiveram excluídos do evento, além do vasto semiárido. Tivemos assim uma copa quase "litorânea", condizente com uma estrutura espacial anterior à era das grandes políticas de interiorização, que têm Brasília como marco, e que se acentuaram posteriormente com a adoção do regime militar. 
Ainda numa abordagem específica da geografia do futebol, tomando agora a escala planetária como referência, um megaevento como este pode elucidar elementos do panorama econômico e geopolítico mundial: a Copa como vitrine das nações mais poderosas, com poucos e pauperizados representantes africanos, por exemplo. Para IgnacioRamonet (1998:55), a Copa do Mundo é uma autêntica "guerra ritualizada", que reafirma o futebol como o melhor revelador das virtudes de uma nação. Pode ainda revelar anseios geopolíticos de projeção internacional: tal qual a Itália fascista com a Copa de 1934, e a Alemanha nazista, que realizou em 1936 a maior olimpíada jamais vista até então, o governo Vargas pretendeu realizar uma Copa do Mundo em 1942 como genuína propaganda do Estado Novo, mas teria sido contido pela eclosão da Segunda Guerra Mundial, que suspendeu a realização do certame (Drumond, 2009).

O estudo da Copa centrado no espaço intraurbano, por sua vez, lida com o amplo (e por vezes dramático, para as comunidades afetadas) pacote de reformas na infraestrutura da cidade, com destaque para projetos de mobilidade, no caso brasileiro para o grande evento de 2014. Poder-se-á investigar a espacialidade futebolística existente e o impacto do certame sobre o parque de estádios. Este será o foco central deste trabalho, uma vez que em 1950 o porte deste evento não acionava grandes orçamentos de modo a intervir na infra-estrutura urbana. Não deixaremos, todavia, de tecer ligeiras observações e comentários sobre a rede urbana brasileira, e como esta foi acionada para dar suporte a este megaevento. Em nosso exercício, tentaremos situar a Copa de 1950 no contexto de nossa urbanização, enquadrando as intervenções materiais (criação e reforma de estádios) e a própria escolha locacional das cidades-sede no contexto do Brasil urbano de então.

Para aquilatar a inserção da Copa na produção do espaço urbano, começaremos apresentando o quadro preexistente em nossa espacialidade futebolística, ou seja, como eram nossos estádios quando o Brasil decidiu organizar o certame. Esta retrospectiva permitirá dimensionar com mais clareza o impacto da copa no parque de estádios brasileiro. A seguir, traçaremos um breve panorama do processo de popularização do futebol no Brasil, que a partir dos anos 1930 demandou a criação de uma nova geração de estádios. Por fim, identificaremos as intervenções que a Copa de 1950 promoveu em nossos estádios, para argumentar que a realização deste evento muito pouco alterou o processo em curso de renovação de nosso parque de estádios. 


\section{A modernidade urbana e a primeira geração de estádios no Brasil}

O futebol se introduziu no Brasil entre o final do século XIX e começo do seguinte, enquanto modismo europeu com traços higienistas, moralistas, cosmopolitas e de distinção social, bem mais adequado, portanto, aos jovens da elite (Mascarenhas, 2001). Naqueles primeiros anos, o futebol se constituía veículo sedutor de promessas civilizatórias e libertadoras. Promessas de modernidade e de progresso. Neste sentido, trabalhadores ingleses, missionários estrangeiros e jovens bacharéis trouxeram da Europa não apenas a prática de um novo esporte, mas sobretudo sua dimensão simbólica: o futebol como atividade portadora de benefícios incontestes posto que oriundo da "boa" civilização européia, tomando-o como atividade saudável e capaz de aprimorar a inteligência, o caráter e outros atributos morais. Segundo Hobsbawm (1988, p.53), "o mundo estava dividido entre uma parte menor, onde o 'progresso' nascera, e outras, muito maiores, aonde chegava como conquistador estrangeiro, ajudado por minorias de colaboradores locais (...) grupos de paladinos dos novos hábitos". Aqueles jovens pertencentes a famílias de elevado poder econômico, fundadores de vários clubes de futebol no Brasil, podem ser enquadrados neste grupo.

Chancelado pelos grupos pretensamente modernos e "cosmopolitas", o futebol aporta no Brasil justo no momento em que as elites brasileiras querem investir abruptamente na ruptura com o passado colonial. Por conseguinte, praticam o futebol de forma altamente segregada, falando inglês, como um autêntico ritual de distinção de classe.

Nesse sentido, nossos primeiros estádios eram destinados quase que exclusivamente às elites. Sua geografia é inequívoca: localizados nos bairros mais nobres, e como equipamentos de pequeno porte (geralmente uma única estrutura edificada que sequer cobria toda a extensão de um dos quatro lados do campo), apresentavam uma arquitetura mais assemelhada a um confortável teatro, porém a céu aberto. Como os atletas eram igualmente egressos das camadas sociais privilegiadas, eram seus familiares e amigos que compareciam para assistir às exibições do novo sportinglês que fazia sucesso na Europa. O estádio era então um ornamento da onda civilizadora de cunho eurocêntrico, e de acesso muito restrito. Verdadeiro espaço de fruição das elites (MASCARENHAS, 2009). 
Inúmeros exemplos atestam este momento inicial da história dos estádios no Brasil. Em Porto Alegre, o Grêmio Football Porto Alegrense ergue em 1904 seu primeiro estádio, o primeiro de toda a Região Sul, um majestoso pavilhão social com apenas quinhentos assentos e situado em zona nobre (bairro Moinhos de Vento), tendo como vizinho imediato o elegante hipódromo da cidade ${ }^{\text {iv }}$. Em São Paulo, as primeiras partidas aconteceram no final do século XIX, no Velódromo, em terreno pertencente à poderosa família Prado, no bairro da Consolação, quando esta zona estava sendo ocupada por mansões no contexto de expansão urbana de cunho burguês-higienista, para fora do velho centro e longe da cidade que se industrializava para além da Várzea do Carmo, no sentido leste. Já em 1902, a companhia Antártica, que acolhia partidas de futebol em seu Parque destinado ao lazer dos funcionários, será o palco dos jogos do primeiro campeonato paulista de futebol, resultando, a seguir, na edificação do Estádio Parque Antártica, provavelmente o primeiro estádio de futebol na historia do Brasil.

Não obstante o engajamento da mocidade aristocrática, a espacialidade do futebol brasileiro em seus primórdios era marcada pela improvisação. Sendo uma atividade ainda incipiente, com poucos jogos ao longo de cada ano, e atraindo ainda um público reduzido, não havia justificativa para investir na construção de equipamentos específicos. O resultado foi a adaptação de espaços (nobres, claro) para o jogo. Edificar um estádio presume elevado investimento, que eventualmente poderia ser proveniente de um rico mecenas, como a família Guinle, no Rio de Janeiro, que patrocinou a edificação do elegante estádio do Fluminense Football Club, em 1906.

Neste quadro de improvisações, em São Paulo havia, como dissemos, um equipamento esportivo, o Velódromo, que serviu para abrigar os primeiros movimentos do cenário futebolístico local. Em Recife, as partidas de futebol eram disputadas na “Campina do Derby", espaço adaptado de um dos antigos hipódromos da cidade. O uso de tais espaços decorria sobretudo da existência de superfícies extensas e planas o suficiente para se jogar o futebol, além da disponibilidade prévia de setor de assentos para a seleta assistência. Mas para além da praticidade, havia também o significado simbólico, a referendar o novo esporte: o futebol sendo uma modalidade aceita no círculo privilegiado das elites, que se incluía no rol das modalidades já consolidadas na vida social e esportiva local. 
$\mathrm{Na}$ maioria das cidades, devido à ausência de equipamentos esportivos, os primeiros praticantes do futebol recorriam a espaços livres. Na Paraíba, os primeiros jogos ocorreram em 1908 na Praça Independência, na capital, tomando de empréstimo algumas cadeiras do Teatro Santa Rosa (Marques, 1975, p. 15). O mesmo ocorreu em Salvador, onde o Campo da Pólvora serviu como palco das primeiras exibições do football, para mais tarde se instalar no Hipódromo do Rio Vermelho. Em Porto Alegre, o Parque Farroupilha também acolhia jogos, mesmo quando já existia o estádio da Baixada, devido à multiplicação de clubes na cidade por volta de 1909. Em Curitiba, a primeira partida teria ocorrido em 1905, no Bosque da Rua Marechal Deodoro, mas a seguir se definiu o Jóquei Clube Paranaense como local preferido dos jogos, que contavam ainda com o campo do Quartel da Força Pública.

Segundo o almanaque de Audinho e Klein (1986), na cidade de Manaus, os primeiros jogos de futebol ocorreram no prado do Dispensário Maçônico, mas contavam também com espaços na Praça da Saudade e o Bosque Municipal. Em Fortaleza, o espaço utilizado pelos primeiros "footballers" situava-se em frente ao Gasômetro, a partir de 1904. Mais tarde, com a atividade consolidada, os clubes dispunham do "Stadium do Prado". Em Florianópolis, improvisava-se na Praça General Osório. E a capital goiana, em 1907, conhecia o futebol por um grupo de rapazes que se exibiram no Largo do Chafariz. Neste caso, nota que revela o grau de incipiência e improvisação: apenas seis jogadores em cada time.

Em suma, diversos foram os expedientes dos interessados em praticar o futebol para encontrar um espaço plano, amplo e compatível com as regras vindas da Inglaterra. Notamos o uso de praças e parques, mas sem dúvida os hipódromos foram espaços privilegiados para abrigar a nova modalidade. No entanto, este equipamento era restrito às cidades onde o turfe estava consolidado, como em Recife, Fortaleza e Curitiba. São Paulo dispunha de um velódromo, e o Rio de Janeiro contou com o mecenato para erguer um estádio para o seu primeiro clube de futebol.

Desta primeira geração de estádios, poucos sobreviveram, como o do Fluminense F.C., no Rio de Janeiro. Situados em zonas nobres, geralmente as de maior valor imobiliário, que mais tarde se submeteriam a processos de verticalização, tais estádios, uma vez substituídos por equipamentos maiores, de caráter "popular" e situados em locais menos valorizados, tenderam à demolição, para abrigar lucrativos 
projetos imobiliários. No caso de Porto Alegre, o estádio Moinhos de Vento, que sobreviveu até 1954, deu lugar ao requintado parque homônimo, garantindo assim a valorização do bairro, que se manteve como o mais nobre da capital até aproximadamente a década de 1990, quando se consolidam novos bairros no mesmo vetor leste, dotados das novas amenidades requisitadas pelo mercado.

O processo de popularização do futebol iria inevitavelmente tornar estes estádios anacrônicos. Por um lado, sua reduzida capacidade de público não comportaria mais o crescente afluxo de interessados a assistir os jogos. Por outro, a ampliação destes equipamentos encontrava obstáculos físicos, pois geralmente estavam inseridos em zonas de densa ocupação, bairros tradicionais. Ao mesmo tempo, o fato de estarem situados em zonas nobres, encarecia qualquer projeto de ampliação que requisitasse aquisição de terreno para expansão do estádio. Por fim, o próprio afluxo maior e mais ruidoso de torcedores não interessava aos habitantes destes bairros nobres, pois comprometia suas valiosas amenidades. Ademais, conforme o futebol ia deixando de ser o esporte dos jovens aristocráticos, não seria mais interessante comportar nestes bairros um estádio, ao contrário dos hipódromos, e mais tarde dos campos de golfe, que permanecem como equipamentos esportivos valorizadores das imediações. Em suma, a evolução social do futebol e sua espetacularização demandavam uma nova espacialidade, tratada a seguir.

\section{A popularização do futebol e sua condição espacial: novos e maiores} estádios

O movimento esportivo de uma determinada cidade, quando alcança certo êxito e popularidade, resulta na criação de grandes objetos geográficos destinados a exibir e "vender" o espetáculo, com destaque para hipódromos, velódromos, ginásios cobertos e estádios de futebol. Mas nem sempre tais objetos têm existência duradoura na paisagem urbana, uma vez que dependem da permanência das condições históricas que os geraram. No caso do turfe, houve grande sucesso em diversas capitais brasileiras no final do século XIX, mas parece que o futebol conquistou muitos de seus admiradores, transferindo para os estádios parte expressiva do público que freqüentava as corridas de 
cavalo. Recife, por exemplo, chegou a contar com três prados em 1901, mas todos foram abandonados, pela queda no movimento de apostas $\mathrm{v}$.

O futebol, ao contrario do turfe, do ciclismo e do remo, seguiu seu curso evolutivo numa ascendente constante, adquirindo níveis de popularidade que desafiavam a base geográfica existente. No processo de popularização do futebol, que se consolida nas décadas de 1920 e 1930, um marco importante não apenas para o Rio de Janeiro, mas para o conjunto da nação, foi a inauguração do estádio São Januário pelo C.R. Vasco da Gama, em 1927. De grande porte para a época (o maior da América do Sul até a inauguração, no ano seguinte, do estádio do clube argentino Independiente, na Grande Buenos Aires), dotado de linhas arquitetônicas imponentes, o equipamento estava localizado em zona industrial e de média-baixa renda, estabelecendo assim uma ruptura acentuada com o padrão locacional até então vigente para os estádios brasileiros. Segundo Fernando Ferreira (2004, pp. 73-4), alguns fatores básicos intervieram na escolha do local:

"Obairro de São Cristóvão perdera definitivamente qualquer resquício do outrora bairro imperial, aristocrático (...)assumira o papel de bairro industrial e proletário, passando a ser ocupado por uma população predominantemente de origem operária, com as antigas propriedades anteriormente pertencentes aos nobres e aos cidadãos mais abastados, sendo gradativamente substituídas por indústrias e pela população com menos recursos. A combinação entre a disponibilidade de grandes terrenos a preços acessiveis, nos "fundos" do bairro, com a facilidade de acesso proporcionada pelo transporte feito por bondes, somado à sua grande infraestrutura, ao nosso ver, parecem ter sido fatores determinantes para a escolha de São Cristóvão como sede para o imponente estádio do clube. (...) a relativa proximidade com o antigo campo da Rua Morais e Silva e com a zona portuária, parte da cidade onde o clube fora fundado; a existência de uma numerosa colônia portuguesa em São Cristóvão, composta tanto por moradores quanto por comerciantes e industriais; a identificação do bairro com Portugal, construída desde a chegada da Família Real à Quinta da Boa Vista, na primeira década do século XIX”.

Com capacidade para 50 mil pessoas o estádio se tornaria, imediatamente, uma espécie de palco e vitrine para o populismo. Diversos políticos, com destaque para Getulio Vargas, utilizaram o estádio para grandes manifestações cívicas. No âmbito do futebol, representava a inédita ascensão e poderio de um clube suburbano, o Vasco da Gama. Este clube, como os demais clubes suburbanos dos anos 1920, recrutava atletas 
entre as camadas populares, ao contrário dos tradicionais clubes da zona sul carioca (Fluminense, Botafogo, Flamengo e mesmo o América, de um bairro da zona norte, mas de classe média-alta, a Tijuca). Desde meados da década anterior estas agremiações suburbanas, "morenas", freqüentavam a divisão principal da liga, mas sem o êxito alcançado pelo Vasco, campeão carioca de 1923. Uma conquista que abalou os alicerces do sistema futebolístico de então.

Outro marco importante deste período é a construção do estádio do Pacaembu, em São Paulo, inaugurado em 1940. Consoante com o espírito de revolução de 1932 e com todo o discurso bandeirante ufanista de "locomotiva do Brasil", a municipalidade paulistana erigia o primeiro estádio de futebol estatal do Brasil. Todavia, ao contrario do Vasco, o faz em zona nobre da cidade, repetindo a tendência locacional da primeira geração dos estádios. Tratava-se de um monumento cívico, que como tal, exigia uma localização "condizente" com sua importância e centralidade na vida social e cultural da cidade. E não havia apenas o campo de futebol, mas instalações para outras modalidades como atletismo e natação (piscina olímpica), além de um ginásio poliesportivo, já que o objetivo divulgado era a promoção de uma juventude mais saudável, vibrante e, por isso, presumivelmente patriota. Nas palavras de Vargas, imbuído de ânimos fascistas, por ocasião do discurso de inauguração do estádio, se projetava uma mocidade com "elevado índice eugênico" (NEGREIROS, 1998, p.87).

Um ano depois, o governador fluminense Amaral Peixoto, genro de Getulio Vargas e por ele nomeado interventor federal, inaugurava na capital, Niterói, o estádio Caio Martins. Guardadas as devidas proporções, seguia os mesmos princípios que formataram o projeto do Pacaembu: a localização nobre (em Icaraí), as linhas sóbrias, a existência de um verdadeiro complexo esportivo, o controle estatal e o uso do estádio para manifestações cívicas pró-governo. Em linhas gerais, no âmbito da espacialidade do futebol espetáculo, este era o Brasil às vésperas da copa de 1950. Vejamos doravante como este evento impactou a espacialidade futebolística que já se encontrava em plena expansão. 


\section{A Copa de 1950 e sua inscrição na paisagem urbana brasileira}

O grande legado físico de 1950, o complexo esportivo do Maracanã, é um objeto geográfico que pode ser lido como a síntese de uma combinação peculiar de fatores. Um deles, a intensa rivalidade com São Paulo ${ }^{\text {vi }}$, a produzir nos cariocas o sentimento de insatisfação por, mesmo sendo a mais importante urbe nacional, não possuir estádio maior. E, importante frisar, não ter ainda edificado um estádio público (estatal), a simbolizar o valor do esporte para o conjunto da sociedade, isto é, para o projeto de nação civilizada. Estádios privados, sendo propriedade de clubes, eram considerados na época um paradoxo em relação aos elevados princípios esportivos de equidade de condições entre oponentes ${ }^{\text {vii }}$. Outro fator essencial é o crescimento do afluxo de torcedores, evidenciando a necessidade de maiores estádios no Rio de Janeiro.

Não por acaso, em 1941, muito pouco depois da inauguração do Pacaembu, o governo federal, através do Ministro da Educação e Saúde Gustavo Capanema, lançou concurso para escolha do melhor projeto para o futuro Estádio Nacional no Rio de Janeiro. A iniciativa, entretanto, naufragou diante das disputas políticas entre esferas de governo, já que a municipalidade imediatamente declarou interesse e determinação em construir o grande estádio da capital (MOURA, 1998, p.24). Ao mesmo tempo, os principais clubes da cidade vinham cogitando ampliar seus estádios, cogitando equipamentos com capacidade para cem mil pessoas, mas estancaram seus projetos diante do anuncio do interesse estatal em edificar uma grande arena de uso comum.

Outro fator a se destacar na produção do que seria o maior estádio do mundo é o momento histórico do país, embalado pelo desenvolvimentismo e pela perspectiva de se alinhar às grandes nações "operosas" e civilizadas. A industrialização movida pela substituição de importações, a velocidade do êxodo rural e a conformação de uma máquina estatal cada vez mais atuante, todos esses movimentos delineavam um quadro otimista. E neste otimismo, a aceitação de projetos monumentais que viessem exibir ao mundo nossa grandeza e nossa capacidade técnica. Assim, edificar o maior estádio do mundo estaria em plena consonância com o futuro imediato do "gigante adormecido".

Criticou-se o projeto do estádio, sob alegação de prioridade de investimento público em setores básicos, como saúde e educação (MOURA, op.cit., p.28). Mas os argumentos em contrario revelam outro fator conjuntural a favorecer a construção do 
estádio: a vigência do discurso regenerador do esporte (que remonta ao século XIX, mas que foi reanimado pelo nazi-fascismo), e sua paradoxal atribuição à modalidade "futebol" que, por suas características intrínsecas (de choques imprevisíveis, de variações constantes de batimento cardíaco e esforços exagerados), não é bem acolhido pela medicina como promotor de saúde, tampouco recomendado como ingrediente formador do caráter. Outra contradição neste discurso que associa construção de estádios com saúde pública é o fato de este equipamento estimular a passividade e não a prática esportiva. A vitória deste frágil argumento revela a força da ideologia do esporte como formador de um Novo Homem no contexto do Estado Novo. E o Maracanã como símbolo de uma nova era de civilidade e engrandecimento da nação.

Por fim, vale citar a rivalidade entre Brasil e Argentina. Ambos disputaram a condição de sede da Copa de 1950, mas vencemos não obstante as melhores instalações e infraestrutura geral do país vizinho, que dispunha de melhor nível de desenvolvimento material e maior estagio de evolução da "cultura futebolística", dispondo de estádios bem maiores que os nossos. Mediante os constantes atrasos e hesitações brasileiras, os argentinos, inconformados com a derrota, reafirmavam seu interesse em sediar a Copa (MOURA, 1998, p.33), de forma que assegurar a realização do certame tornara-se uma questão crucial de orgulho nacional. Enfim, o gigante de concreto era também uma vitória sobre o pretensioso rival do sul, a nação que presumivelmente se julgava superior ao Brasil (e de fato apresentava indicadores sócio-econômicos muito superiores), inclusive racialmente no discurso de então.

Alem do Rio de Janeiro, foram sedes da copa as cidades de São Paulo (com o estádio Pacaembu, de 1939), Curitiba (estádio Durival Brito e Silva, de 1947), Porto Alegre (estádio dos Eucaliptos, de 1931), Recife (estádio Ilha do Retiro, de 1937) e Belo Horizonte (estádio Independência, de 1950), este último sendo o único construído especificamente para a Copa. Explica-se a excepcionalidade mineira: por um lado, Belo Horizonte, cidade inteiramente planejada, era o ostentado símbolo maior da modernidade urbana nacional (antes da construção de Brasília) e capital de uma das mais importantes unidades da federação, política, histórica e economicamente falando. Esta cidade em crescimento vertiginoso, símbolo do progresso, que caminhava velozmente no sentido da polarização das diversas bacias urbanas de Minas Gerais, 
conformando paulatinamente um único sistema urbano para consolidar sua centralidade (SINGER, 1974), não dispunha ainda de um estádio compatível.

O futebol ainda se encontrava em estágio relativamente atrasado de desenvolvimento na capital mineira. Notar que em 1929 se inaugurou um estádio com capacidade para apenas cinco mil pessoas, pertencente ao clube mais popular do estado, o Atlético-MG (ZILLER, 1974, p.26). A almejada afirmação de Belo Horizonte no contexto das nascentes metrópoles nacionais implicava seguir o exemplo então recente de São Paulo (e já em curso no Rio de Janeiro) e assim erigir um "grande" estádio municipal, equipamento que iria se alinhar com outras obras monumentais, dignas de um centro urbano moderno e civilizado. A Copa do Mundo foi, sem dúvida, um grande pretexto e fato impulsionador do projeto.

Antes de tratar das demais sedes, cabe citar o estádio Fonte Nova, em Salvador. O atraso nas obras impediu, infelizmente, sua participação na Copa de 1950, sendo inaugurado apenas seis meses após o certame, em janeiro de 1951. A Bahia seguiria os mesmos passos supracitados do Pacaembu, Caio Martins e Maracanã, ao inaugurar o monumental estádio estadual Otavio Mangabeira, dotado não apenas de complexo esportivo, mas também de estabelecimento escolar público. De linhas modernistas, sua localização é central e emblemática, ao lado do Dique do Tororó.

Os demais estádios da Copa apenas sofreram adaptações, tais como colocação de alambrados e eventual criação de túneis e espaços apropriados para jornalistas, equipamentos básicos exigidos pela FIFA que, ao que consta, teria feito uma única visita previa de vistoria de cada um dos seis estádios. O estádio dos Eucaliptos, excepcionalmente, sofreu ampliação significativa, passando sua capacidade de público de 10 mil para 30 mil espectadores, e trocando setores de arquibancada ainda de madeira por estruturas de concreto. Mas tal reforma se explica não exatamente pela realização da Copa, mas pelo rápido crescimento do clube proprietário, o S.C. Internacional, fenômeno que merecerá atenção nos próximos parágrafos, por ser representativo do contexto de popularização do futebol e de formação das grandes torcidas.

O Internacional de Porto Alegre surgiu em 1909, como iniciativa de indivíduos de classe média para desafiar o Grêmio F.P.A., então principal força do nascente futebol gaúcho e representante das elites alemães que então controlavam importantes setores da 
economia. Desde o inicio, portanto, o Internacional procura se impor como o "clube nativo", representante dos segmentos luso-brasileiros, contra o clube dominante, “estrangeiro". Na década de 1930, este clube investiu no processo de popularização de sua imagem, com êxito peculiar.

Em 1931, ao inaugurar seu novo estádio (o "Estádio dos Eucaliptos"), o Internacional dava um passo importante na afirmação de sua popularidade, por duas razões básicas: localizava-se no subúrbio Menino Deus, enquanto seu rival mantinha-se em zona nobre, conforme acabamos de demonstrar. Já em 1935, um Gre-Nal decisivo realizado no estádio lotado da Baixada registrou que 2/3 dos presentes, ainda que em "território inimigo", eram torcedores do Internacional. Evidenciava-se no "clube nativo" o pleno potencial de tornar-se um "clube do povo" (COIMBRA e NORONHA, 1994).

De posse de novas perspectivas, o Internacional resolve absorver os "ventos populares da Campanha Gaúcha". Naquela década de 1930, os clubes de Pelotas, Rio Grande, Livramento e Bagé conquistaram sete dos dez campeonatos estaduais disputados anualmente ${ }^{\text {viii }}$. A razão principal para esta incômoda superioridade "latifundiário-pastoril" sobre o futebol da capital se amparava na forte influência platina, além, é claro, do poder econômico dos latifundiários da Campanha. Aderindo ao modelo "profissionalista" já consolidado no Prata desde o final da década anterior, tais clubes investiam abertamente na contratação de jogadores talentosos, sem qualquer restrição relacionada a raça ou origem social do atleta. Contando com financiamento dos grandes pecuaristas, o futebol da Campanha estendia sua base de recrutamento para além da fronteira, inserindo em suas equipes jogadores uruguaios (e eventualmente argentinos) de excelente nível técnico ${ }^{\mathrm{ix}}$.

Em Porto Alegre, o futebol se mantinha estruturado em ligas diferenciadas que operavam como circuitos independentes, reproduzindo a rígida hierarquia sócioeconômica vigente na cidade. A liga principal funcionava dentro dos princípios "amadorísticos", mas a pressão crescente dos novos torcedores desejosos de vitórias já orientava no sentido da incorporação de outros valores. Como bem percebeu Arlei Damo (1998, p.109), o prestígio de um clube começava a ser aferido por critérios de ordem quantitativa (triunfos e quantidade de torcedores), e não mais pela distinção de seus partícipes. Progressivamente, as massas urbanas da metrópole em formação se interessam pelo futebol e o redefinem. 
Não somente a Campanha Gaúcha oferecia alternativas ao modelo amador vigente na capital. Naquela década de 1930 se consolidava a inserção do negro nos grandes clubes de futebol de Rio de Janeiro e São Paulo. O maior ídolo brasileiro, consagrado na Copa do Mundo de 1938, era então Leônidas da Silva, não apenas um jogador de cor negra, mas um cidadão de índole rebelde que resistia em negar sua origem humilde e sua negritude. Abria-se progressivamente um novo horizonte para os atletas negros no futebol brasileiro.

Bem menos atrelado a valores elitistas que seu rival, coube ao Internacional, mais precisamente a partir de 1937, a iniciativa de recrutar maciçamente jogadores negros e pobres para reforçar sua equipe. O resultado óbvio é um verdadeiro "massacre" em seu adversário, ao conquistar ao longo da década seguinte nove dos dez campeonatos citadinos disputados. Ao adotar jogadores negros e pobres, o clube rapidamente se tornou nos anos 1940 o "clube do povo" de Porto Alegre. Outros símbolos viriam endossar esta nova imagem: o famoso rei momo Vicente Rau tornou-se líder da torcida, animando as arquibancadas em tom carnavalesco; um animal desprovido de qualquer nobreza como a cabrita, se tornou "mascote" do time, acompanhando-o em todos os jogos, entrando em campo e tornando-se popularmente conhecido com o nome de "Chica" (COIMBRA e NORONHA, 1994, p.51). O negrinho, expressiva figura do folclore regional, expressão da humildade, - e posteriormente (em 1968) o saci, a representar a malícia e os poderes obscuros de uma negritude excluída - foi adotado nos anos 50 como símbolo máximo do clube.

E assim o futebol porto-alegrense ingressou em novo período, distanciando-se radicalmente do obsoleto tom aristocrático e elegante, expressão da modernidade européia (excludente), para "carnavalizar" os estádios e neles inserir definitivamente o anonimato ruidoso das multidões ${ }^{\mathrm{x}}$. Neste sentido, podemos afirmar que a Copa do Mundo apenas ofereceu um contexto que oportunizou a realização de um investimento material que não tardaria a acontecer: a inexorável ampliação do Estádio dos Eucaliptos. Bem como urgia, no Rio de Janeiro e em Belo Horizonte, a construção de um estádio condizente com o porte e as funções destas duas capitais. 


\section{Considerações finais}

Em suma, a Copa de 1950não imprimiu, de forma significativa, novos rumos ao futebol brasileiro e sua espacialidade. Tentamos aqui demonstrar que um processo de renovação de nosso parque de estádios já estava em curso, com pelo menos duas décadas de antecedência em relação ao referido megaevento. Tal renovação, basicamente ditada pela ampliação física dos equipamentos e dotação de maior espaço para os setores populares, respondia ao processo gradual de ressignificação do futebol na sociedade brasileira: de um esporte praticado pela e para deleite das elites, o futebol foi progressivamente despertando interesse nos setores populares. Paulatinamente, atletas egressos da "várzea" e dos subúrbios vão ingressar nos principais clubes, tornando os times "mestiços". Ao mesmo tempo, os segmentos populares se interessam em participar como elementos ativos do espetáculo, enquanto as elites descobrem outras modalidades de clara distinção social, como a natação, o tênis e o golfe.

Na medida em que os estádios vão se preenchendo de gente que trabalhava nas fábricas, na construção civil e no mercado informal da metrópole em construção, esta efetivamente vai incorporando o futebol em seus novos e complexos mecanismos de reprodução social. Parecia assim seguir o futebol as novas tendências estruturais, que apontavam para a transição no sentido de uma cultura urbana de massas. Nas palavras de Sandra Pesavento (1991, p.72), até a década de 1940 a cidade de Porto Alegre mantém-se cindida no âmbito das formas de sociabilidade e de entretenimento: de um lado o Joquei Club, o Yacht Club, os cafés, cinemas e teatros, e de outro o botequim, os banhos no Guaíba, as rinhas de galo e o carnaval de rua. Neste cenário segregado, apenas "as programações radiofônicas congregavam boa parte desses segmentos, transformando-se em veículos de uma cultura nacional-popular". A partir desta década, processos de relativa integração social vão se desenvolvendo e gerando novos espaços de sociabilidades. Acreditamos que os novos estádios de então, por seu porte e capacidade de aglutinar os diversos segmentos sociais, participam ativamente da transição de uma cidade culturalmente segregada (vide as reformas urbanas da Belle Époque) para um novo urbano, de nuances fordistas e dotado de elementos de uma cultura "de massas". Mas nesta linha de análise pretendemos investir com mais propriedade nos próximos passos da pesquisa ${ }^{\mathrm{xi}}$. 
Pela própria natureza relativamente modesta dos megaeventos esportivos anteriores ao advento da nova economia globalizada do futebol, a realização da Copa do Mundo em 1950 não apresentou impacto expressivo em nossos estádios. Já estava em curso a afirmação de uma política voltada para a construção de estádios maiores. Nossa hipótese é a de que, mesmo sem a copa, o Brasil teria seguido o mesmo curso de evolução no sentido de se tornar o detentor do maior parque de estádios do mundo nos anos 1970.

A espacialidade da Copa retrata, de alguma forma, o panorama da rede urbana brasileira em meados do século XX, tema que poderá ser melhor explorado em estudos posteriores. A forte concentração de investimentos e mesmo de partidas disputadas, no Rio de Janeiro, expressa não apenas a condição de capitalidade, mas a própria força da urbe carioca no cenário econômico, social e cultural de então. As duas metrópoles nacionais concentraram dois terços de toda a competição. O empobrecido Nordeste compareceu "simbolicamente" com uma única cidade (Recife), com um estádio improvisado (Ilha do Retiro) e acolheu uma única partida, do total das 22 disputadas. A região Sul, a segunda mais desenvolvida, contou com duas cidades (Porto Alegre e Curitiba), mas acolheu apenas quatro partidas, ou seja, reduzida participação no certame, que teve o Sudeste como "centro". À precariedade da rede de comunicações devemos somar a baixa capacidade orçamentária do evento esportivo.

Acreditamos também que a copa representou, no cenário internacional, a afirmação do Brasil como potência emergente, no futebol, na engenharia civil e na economia. O desenvolvimentismo que caracterizou a década de 1950 não pode ser desvinculado deste evento, e em especial da construção de um estádio que, por muitas décadas, se manteve como o maior do mundo. Também no contexto nacional, esta copa representa a consolidação do futebol como instituição onipresente no território e como incontestável paixão nacional. Pode ser lida como o autêntico desfecho da política "esportiva" do Estado Novo, que a concebeu dentro do espírito do fascismo italiano: futebol como elemento crucial de fomento do patriotismo e de mobilização das massas.

Finalizamos nossas reflexões com uma brevíssima comparação com a Copa de 2014, que revela, ao seu modo, as profundas transformações operadas na urbanização brasileira nos últimos 64 anos. Poderíamos explorar inúmeros aspectos, como o processo de interiorização e maior integração do território nacional, que permitem 
englobar todas as macrorregiões no certame, bem como a distribuição espacial bem menos concentradora das partidas. Todavia, o que nos parece mais importante neste ligeiro esforço de comparação, é notar o papel do Estado na produção do espaço urbano, particularmente no tocante às políticas de bem-estar social.

Em 1950, o Brasil vivia os primórdios do que seria mais tarde, nos anos do regime militar, a formação da máquina estatal planejadora do território nacional e das cidades. A presença estatal no futebol daria, como vimos, seus primeiros passos ao edificar estádios como o Pacaembu, em São Paulo, em 1940. Para além da construção do Maracanã, teve tímida participação da na copa de 1950, mas se agigantou a partir de 1968, com a disseminação de grandes estádios populares em praticamente todas as capitais, numa evidente política de "pão e circo". A edição de 2014 revela maciça participação governamental, sobretudo no volume de recursos, porém não para oferecer diversão para as massas urbanas. Os novos estádios se destinam a segmentos com maior capacidade de consumo, e tendem a ser geridos pela iniciativa privada. Em suma, tínhamos em 1950 o esboço de um Brasil urbano marcado, ao menos em alguns setores, por políticas públicas orientadas para a inclusão das camadas populares, como por exemplo, na provisão de habitação social dotada de serviços públicos essenciais como saúde e educação. O novo cenário aponta para um contexto nitidamente neoliberal no qual as políticas e investimentos públicos favorecem a iniciativa privada e promovem segregação socioespacial, elitizando os estádios e utilizando a copa do mundo para executar projetos urbanos que acentuam as desigualdades sociais na cidade.

\section{Referências}

ANDRANOVICH, G., BURBANK, M. e HEYNG, C. Olympic cities: lessons learned from Mega-Event Politics. Journal of UrbanAffairs, v.23, n.2, pp. 113-131, 2001.

ANDRANOVICH, G.,.Mega-events, urban development, and public policy. In: The Review of Policy Research., 19:3, fall 2002. p. 179-202.

AUDINHO, Sérgio e KLEIN, Marco.O Almanaque do Futebol Brasileiro. São Paulo: Escala, 1996. 
BOURDIEU, Pierre. Como é possível ser esportivo? In: Questões de Sociologia. Rio de Janeiro: Marco Zero, 1983, pp. 136-153.

COIMBRA, David e PINTO, Antonio. História dos Grenais. Porto Alegre: Artes e Ofícios, 1994.

DAMO, ArleySander. Para o que der e vier. O pertencimento clubístico no futebol brasileiro a partir do Gremio de Football Portoalegrense e seus torcedores. Dissertação de mestrado em Antropologia Social, UFRGS, 1998.

DRUMOND, M. Pátrias em jogo: esporte e propaganda política nos governos de Vargas e Perón. In: MELO, V. (org) História comparada do esporte. Rio de Janeiro: Shape, 2009.

FERREIRA, Fernando da Costa. O bairro Vasco da Gama: um novo bairro, uma nova identidade? Dissertação de Mestrado em Geografia. Universidade Federal Fluminense, Niterói, RJ, 2004.

GIULIANOTTI, Richard. Sociologia do futebol: dimensões históricas e socioculturais do esporte das multidões. São Paulo: Nova Alexandria, 2002.

HAYNES, Jill. Impacto Socioeconômico de los Juegos Olímpicos de Sydney 2000. Centre d'EstudisOlímpcs i de l'Esport. Barecelona, 2005. http://olympicstudies.uab.es(acesso em 17 de maio de 2005).

HOBSBAWM, Eric. Nações e nacionalismos desde 1870. São Paulo: Paz e Terra, 1991. MARQUES, Valfredo. A História do Futebol Paraibano. João Pessoa: União Cia.Editora. 1975.

MARTIN, André R. Fronteiras e nações. São Paulo: Contexto, 1992.

MARX, Murilo. Cidade no Brasil: terra de quem? São Paulo: Nobel/EDUSP, 1991.

MASCARENHAS, Gilmar. Os jogos pan-americanos de 1963. In: BIENENSTEIN, G., SÁNCHEZ, F. (orgs). O jogo continua: megaeventos esportivos e cidades. Rio de Janeiro: FAPERJ e EdUerj, 2011, pp. 83-97

O novo estádio de futebol: reflexões sobre territorialidade, lugar, cultura e cidadania. In: Maria Geralda de Almeida; Beatriz Nates Cruz.. (Org.). Território e cultura: inclusão e exclusão nas dinâmicas sociespaciais. Goiania e Manizales: Universidade Federal de Goias/FUNAPE e Universidad de Caldas, 2009, v. 1, p. 101-113. 
Tensões e mudanças recentes na cultura e na gestão do futebol brasileiro: entre a tradicional base local e as forças do mercado.. In: GARGANTA J., OLIVEIRA J., MURAD M.. (Org.). Futebol de Muitas Cores e Sabores. Coimbra: Campo das letras, 2004.

A bola nas redes e o enredo do lugar: uma geografia do futebol e de seu advento no Rio Grande do Sul. Tese (Doutorado em Geografia), FFLCH, Universidade de São Paulo, 2001.

. O futebol da Canela Preta: o negro e a modernidade em Porto Alegre (RS). Anos 90, Revista de Pós-graduação em História da Universidade Federal do Rio Grande do Sul (UFRGS), Porto Alegre, n.11, julho de 1999, pp.144161.

MASCARENHAS, G.; RAVENEL, L. ; HELLEUE, B. . Metropolização e futebol. In: SILVA, Catia A.; LOUREIRO, Anita. RIBEIRO, Ana Clara T.. (Org.). Metrópoles: entre o global e as experiências cotidianas.. Rio de Janeiro: FAPERJ, 2012, p. 72-87.

MASCARENHAS, G., BIENENSTEIN, G., SÁNCHEZ, F. 2011. O jogo continua: megaeventos esportivos e cidades. Rio de Janeiro: FAPERJ e EdUerj.

McKAY, M. \& PLUMB, C. Reaching beyond the gold: the impact of the olympic games on real state markets. Centre d'EstudisOlímpcs i de l'Esport. Barcelona, 2005. http://olympicstudies.uab.es

NEGREIROS, Plinio L.C..A Nação entra em Campo: Futebol nos anos 30 e 40.Tese (doutoradoemHistória), PUC-SP, 1998.

OWEN, J.G. Estimating the Cost and Benefit of Hosting Olympic Games: What Can Beijing Expect from Its 2008 Games?The Industrial Geographer, 3 (1) 1$18,2005$.

PERDIGÃO, Paulo. Anatomia de uma derrota. São Paulo: L\&PM, 1986.

PESAVENTO, Sandra J. Muito além do espaço: por uma história cultural do urbano. EstudosHistóricos, 8(16), CPDOC, 1995, pp.279-290.

PREUSS, H. The economics of staging the olympic games: a comparison of the games 1972 - 2008. Cheltenham: Edward Elgar, 2004. 
PRONI, Marcelo W. A metamorfose do futebol. Campinas: Unicamp/Instituto de Economia, 2000, 272 p.

RAMONET, Ignacio. Football et passions nationales. In: BONIFACE, Pascal (org) Géopolitique du Football.Bruxelles: Éditions Complexe, 1998.

SINGER, Paul. Desenvolvimento econômico e evolução urbana. São Paulo: Nacional, 1977, $2^{\mathrm{a}}$ edição, $377 \mathrm{p}$.

STAVRIDES, S. Urban Identities: Beyond the Regional and the Global. The Case of Athens. in: Jamal Al- Qawasmi, Abdesselem Mahmoud and Ali Djerbi (eds.) 2008, Regional Architecture and Identity in the Age of Globalization, Proceedings of $2^{\text {nd }}$ International Conference of CSAAR, Tunis, pp. 577-588.

STEINER, M. THONI, E. Sport as a tool for regional development. In: JEANREHAUD, Claude. The economic impact of Sport Events. Neuchâtel: CIES, 1999.

YOUNG, C.; TOMLINSON, A. Culture, politics and Spectacle in the Global Events. In: (orgs.) National Identity and global Sports Events. New York: N.Y. State University, 2006.

ZILLER, Aldechi. Enciclopédia do Atlético. Belo Horizonte: Lemi, 1974.

\footnotetext{
i O uso do termo "legado" quase sempre denota uma abordagem mais conservadora, ou pelo menos mais alinhada com o pensamento das entidades promotoras, uma vez que o este é o termo que consta nos documentos oficiais de FIFA e COI. A adoção do termo "impacto" resulta geralmente de uma atitude crítica do pesquisador diante dos efeitos "drásticos" do evento sobre o território e a sociedade. Sobre a perspectiva do legado, ver DACOSTA et al (2008). Sobre a aplicação do termo "impacto", temos um exemplo em Haynes (2005), dentre tantos outros.

${ }^{i i}$ Cf. Mascarenhas (2003)

iii De forma inconteste, a principal referencia bibliográfica daquele certame continua sendo "Anatomia de uma derrota" (Perdigão, 1986), título sugestivo de uma obra não-acadêmica, que esmiuçou e documentou a tragédia daquele 16 de julho de 1950, em detalhes e distintos ângulos. No cinema, o destaque fica para premiadíssimo curta "Barbosa", de Julio Furtado, igualmente focado num instante que se eternizou na memória nacional como grande tragédia.

${ }^{\text {iv }}$ Desde que o Barão de Hausmmann edificou no Bois de Bologne o majestoso Hipodromme de Auteuil, conferindo "glamour" ao turfe (tradicional espetáculo popular), se estabeleceu a correlação entre tal objeto e a Belle Époque, difundindo internacionalmente este modelo, de forma que a presença física de um imponente hipódromo passou a ser instrumento de valorização do solo urbano, tendendo a localizar-se em bairros de elite. A respeito, ver Mascarenhas (1999).
}

\footnotetext{
${ }^{\mathrm{v}}$ Revista Sport Club do Recife, 1992.
}

Geo UERJ - Ano 15, nº. 24, v. 2, $2^{\circ}$ semestre de 2013

ISSN: 1415-7543E-ISSN: 1981-9021

http://www.e-publicacoes.uerj.br/index.php/geouerj 
${ }^{\text {vi }}$ Tal rivalidade se expressou em diversos momentos, desde que o futebol começou a adquirir relevo nestas cidades. Em 1915, por exemplo, os paulistas ousaram criar a Federação Brasileira de Futebol, ignorando a capital do país, que dois meses depois fundou a Federação Brasileira de Esportes, com o mesmo objetivo de gerir o futebol em nível nacional. Somente em dezembro de 1916 as duas entidades se fundiram na Confederação Brasileira de Desportos (Santos Neto, 2002: 93).

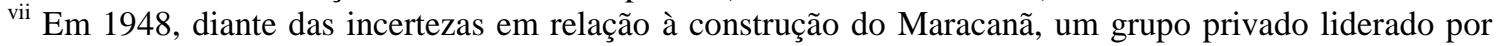
Fausto Matarazzo, anuncia intenção de construir o Estádio Nacional Sociedade Anônima (ENSA), no subúrbio de Irajá, com capacidade para 100 mil pessoas. Projeto duramente criticado pelo Jornal dos Sports, que o acusou de estar em desacordo com os princípios fundamentais da política nacional de esportes.

viii A primeira vez em que uma cidade da metade norte do estado (com exceção óbvia da capital) colocou um clube na decisão do campeonato gaúcho foi em 1942, através do E.C. Floriano, de Novo Hamburgo. Um bem documentado relato da história do campeonato gaúcho de futebol se encontra em Dienstmann (1987).

ix Poderíamos examinar o empenho da elite pecuarista em superar os clubes do futebol da capital como uma faceta do regionalismo gaúcho estudado por Haesbaert (1988): diante da inevitável decadência econômica, restava lutar pela preservação da tradicional hegemonia da Campanha em outros setores, e dentre eles sugerimos o futebol. Trata-se de um tema possível para futuras investigações.

${ }^{\mathrm{x}}$ Em uma de suas provocativas avaliações, o filósofo e cronista esportiva Ruy Carlos Ostermann (apud SC Internacional, 1969:129), quando da inauguração do estádio Beira-Rio, em 1969, afirma que nos novos e gigantescos estádios destinados às massas, o indivíduo não pode mais, pela distância física e pelo ruído da multidão, se comunicar diretamente com os jogadores em campo, exceto se o fizer enquanto coletividade em uníssono, sob o comando de seus reais líderes. Uma "readaptação orgânica e mórfica" do ato de assistir uma partida e participar opinando ou incentivando o time, fazendo-o enquanto coletivo organizado. A única forma, aliás, do trabalhador urbano se expressar politicamente na grande metrópole.

${ }^{x i}$ Projeto "O global e o local na cidade espetáculo:território, cultura e cidadania no contexto da Copa do Mundo 2014. Aprovado pelo CNPq, bolsa de Produtividade em Pesquisa, 2014-2017.

Artigo recebido para publicação em maio de 2013.

Artigo aceito para publicação em agosto de 2013. 